\title{
Study of TSH level at the time of diagnosis of Hypothyroidism in patients with Diabetes Mellitus- A Retrospective Study
}

\author{
K.C.(Adhikari) $\mathrm{I}^{1}$, Ghimire $\mathrm{S}^{2}$, Deo $\mathrm{R}^{3}$ \\ ${ }^{1}$ Associate Prof, Department of Medicine Shree Birendra Hospital chhauni ,Nepal, \\ ${ }^{2}$ Resident, Department of Medicine, Shree Birendra Hospital chhauni, Nepal \\ ${ }^{3}$ Associate Prof, Department of Medicine Shree Birendra Hospital chhauni, Nepal
}

\begin{abstract}
Background: To evaluate the difference in the level of TSH in diabetic and non diabetic patients at the time of the diagnosis of hypothyroidism. Methods: 100 diagnosed cases of hypothyroidism, 50 with diabetes and 50 without diabetes were studied. The level of TSH at the time of diagnosis and other information were obtained from the medical records. Results: The mean TSH in patients with the history of diabetes at the diagnosis of hypothyroidism was $19.9616 \pm 26.990$ and in those without the history of the diabetes was $10.4797 \pm 6.503$ ( $\mathrm{p}$ value 0.018 ). The females with diabetes had higher level of TSH level at the time of diagnosis of hypothyroidism than females without diabetes ( $\mathrm{p}$ value 0.045 ). There was no statistically significant difference in the level of TSH in males with and without diabetes at the time of diagnosis of hypothyroidism. Conclusion: Patients with diabetes mellitus had higher level of TSH at the time of diagnosis of hypothyroidism in comparison to those without diabetes. Early identification of the raised TSH levels in diabetic patients and timely intervention will help to reduce the chances of adverse cardiovascular outcomes and diabetic kidney disease in this group of patients.
\end{abstract}

Key words: Diabetes Mellitus, Hypothyroidism,Thyroid stimulating hormone [TSH]

\section{Introduction}

Thyroid diseases and Diabetes Mellitus are the two endocrine disorders which are frequently encountered in the clinical practice by almost all the clinicians. ${ }^{1}$ These two diseases have effect over each other and this mutual relationship between them has been shown in various studies. ${ }^{1}$ Among various spectrums of the thyroid disorders, hypothyroidism is most frequently found to be associated with the diabetes mellitus. ${ }^{2,3}$

Hypothyroidism is a clinical condition which results from the decreased synthesis of thyroid hormone from the thyroid gland or from the impaired activity of the thyroid hormone at the tissue level. ${ }^{4}$ Overt hypothyroidism is diagnosed when patients have low levels of thyroid hormone and high levels of thyroid-stimulating hormones (TSH). The

Correspondence Author

Col Dr Indu K.C., Associate Prof, Department of Medicine Shree Birendra Hospital chhauni, Nepal, subclinical hypothyroidism is diagnosed when there is elevated thyroid-stimulating hormone (TSH) and normal thyroid hormone level. ${ }^{5}$

The relationship between diabetes and hypothyroidism is a very well established. Patients with diabetes mellitus who have higher levels of $\mathrm{TSH}$ are found to be associated with the increased prevalence of the diabetic kidney disease. ${ }^{6}$ Similarly a study done by Ping Zhu et al. showed the independent association of TSH level with the insulin resistance. ${ }^{7}$

TSH level measurement in blood is the main test used for the diagnosis of the hypothyroidism in the clinical practice. ${ }^{8}$ The use of TSH for the hypothyroidism is preferred because of the various reasons. TSH has inverse log-linear relationship with free-thyroxine (FT4), so small linear decrease in free-thyroxine level causes exponential increase in the TSH level. Similarly, the modern test methods used for the measurement of TSH have more than 99\% sensitivity and specificity. Also, most cases 
Study of TSH level at the time of diagnosis of Hypothyroidism Jour of Diab and Endo Assoc of Nepal 2020; 4 (2): (24-28) of the hypothyroidism encountered in the clinical practice are due to decrease in hormone synthesis by the thyroid gland, making TSH a test of choice. ${ }^{9}$ Within the current study, we aimed to investigate whether there is exists any significant difference in the level of TSH at the time of diagnosis of hypothyroidism among those with and without diabetes mellitus.

\section{Methods and Methodology}

We analyzed retrospectively 100 hypothyroid adult participants of age more than 18 years. 50 patients had diabetes mellitus and remaining 50 without diabetes mellitus were taken as control. All patients were either army personnel, retired armies or their families. All the data were collected on the basis of their medical records. Participants were defined as having T2DM according to self-report, clinical reports, use of anti-diabetic agents and ADA criteria. Serum TSH was estimated by immunoradiometric assay.

Continuous variables were described using means and standard deviations. Chi square test was used for categorical data comparison. ANOVA test was used to compare the means among the groups. P value of $<0.05$ indicates significance. The statistical analysis was conducted with SPSS version 21.0 for Windows. The data were presented and tables and charts.

\section{Results}

Among the total 100 participants in the study, 50 had history of diabetes and 50 didn't have the history of diabetes. Among 100 patients 49 patients were male and 51 patients were females. Out of the 50 patients with diabetes 31 were males and 19 were females. Among the 50 patients without diabetes 18 were males and 32 were females. The mean age of participants with diabetes mellitus was $60.50 \pm 10.42 \mu \mathrm{IU} / \mathrm{mL}$ and without diabetes was $52.54 \pm 15.97 \mu \mathrm{IU} / \mathrm{mL}$. (Table 1 and Table 2)

Table 1. History of Diabetes * Sex of Participant Cross-tabulation

\begin{tabular}{|l|c|c|c|c|}
\hline & & \multicolumn{2}{|c|}{ Sex of Participant } & Total \\
\hline & & Male & Female & \\
\hline $\begin{array}{l}\text { History of } \\
\text { Diabetes }\end{array}$ & Present & 31 & 19 & 50 \\
\cline { 2 - 5 } & Absent & 18 & 32 & 50 \\
\hline Total & & 49 & 51 & 100 \\
\hline
\end{tabular}

Table 2. Mean age of participants

\begin{tabular}{|l|c|c|c|}
\hline $\begin{array}{l}\text { History of } \\
\text { Diabetes }\end{array}$ & Mean & N & $\begin{array}{c}\text { Std. } \\
\text { Deviation }\end{array}$ \\
\hline Present & 60.50 & 50 & 10.420 \\
\hline Absent & 52.54 & 50 & 15.965 \\
\hline Total & 56.52 & 100 & 13.996 \\
\hline
\end{tabular}

The mean TSH in patients with the history of diabetes at the diagnosis of hypothyroidism was $19.9616 \pm 26.990 \mu \mathrm{IU} / \mathrm{mL}$ and in those without the history of the diabetes was $10.4797 \pm 6.503 \mu \mathrm{IU} /$ $\mathrm{mL}$. On comparing the mean difference between these two groups using ANOVA, the $p$ value was found to be 0.018 , which is statistically significant. (Table 3 and Figure 1)

Table 3. Relation between TSH level at diagnosis of hypothyroidism and history of diabetes mellitus

\begin{tabular}{|l|c|c|c|}
\hline $\begin{array}{l}\text { History of } \\
\text { Diabetes }\end{array}$ & Mean & N & $\begin{array}{c}\text { Std. } \\
\text { Deviation }\end{array}$ \\
\hline Present & 19.9616 & 50 & 26.99041 \\
\hline Absent & 10.4797 & 50 & 6.50346 \\
\hline Total & 15.2207 & 100 & 20.10471 \\
\hline $\begin{array}{l}\text { df-1; F-5.832; } \\
\text { p value- } 0.018 ; \\
\text { CI-1.69-17.27 }\end{array}$ & & & \\
\hline
\end{tabular}

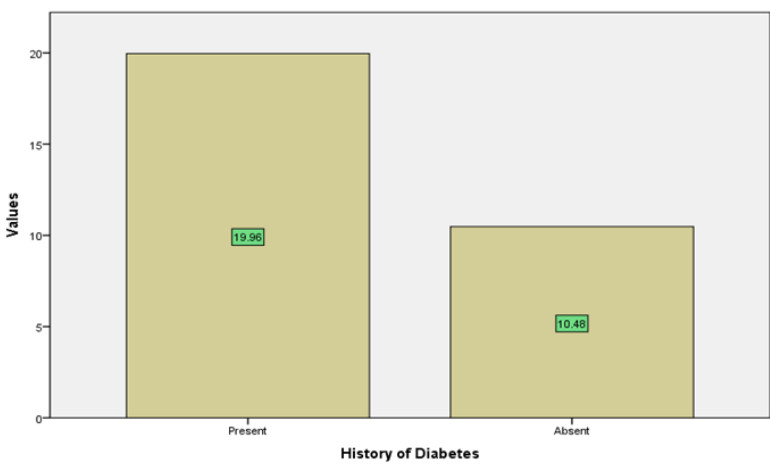

Figure 1. Bar diagram showing mean TSH level on diagnosis of hypothyroidism

In this study, while comparing the mean TSH level among the males with and without diabetes, the mean TSH level among those with diabetes was $17.315 \pm 20.99 \mu \mathrm{IU} / \mathrm{mL}$ and among those without 
diabetes was $9.232 \pm 3.143 \mu \mathrm{IU} / \mathrm{mL}$. The mean difference among these two categories was not statistically significant ( $\mathrm{p}$ value 0.113 ). This implies that there was no statistically significant difference in the level of TSH in males with and without diabetes at the time of diagnosis of hypothyroidism. (Table 4)

Table 4. Difference in TSH level among males with and without diabetes at the time of diagnosis of hypothyroidism

\begin{tabular}{|c|c|c|c|c|c|}
\hline \multirow[t]{2}{*}{ History of Diabetes } & \multicolumn{2}{|c|}{ Sex of Participant } & \multirow[t]{2}{*}{ Statistic } & \multicolumn{2}{|c|}{$95 \%$ Confidence Interval } \\
\hline & & & & Upper & Lower \\
\hline \multirow[t]{3}{*}{ Present } & Male & Mean & 17.3152 & 11.1457 & 25.7020 \\
\hline & & $\mathrm{N}$ & 31 & 31 & 31 \\
\hline & & Std. Deviation & 20.98780 & 5.71590 & 31.45213 \\
\hline \multicolumn{6}{|l|}{ Absent } \\
\hline & Male & Mean & 9.2326 & 7.7633 & 10.7583 \\
\hline & & $\mathrm{N}$ & 18 & 18 & 18 \\
\hline & & Std. Deviation & 3.14274 & 1.87317 & 3.77188 \\
\hline \multirow[t]{3}{*}{ Total } & Total & Mean & 14.3461 & 10.4281 & 19.7306 \\
\hline & & $\mathrm{N}$ & 49 & 49 & 49 \\
\hline & & Std. Deviation & 17.15522 & 5.04543 & 26.08701 \\
\hline
\end{tabular}

df-1; F- 2.613; p value- 0.113

In this study, while comparing the mean TSH level among the females with and without diabetes, the mean TSH level among those with diabetes was $24.280 \pm 34.888 \mu \mathrm{IU} / \mathrm{mL}$ and among those without diabetes was $11.181 \pm 7.748 \mu \mathrm{IU} / \mathrm{mL}$. The mean difference among these two categories was statistically significant ( $\mathrm{p}$ value 0.045). This implies that there was statistically significant difference in the level of TSH in females with and without diabetes at the time of diagnosis of hypothyroidism. Thus, the females with diabetes have higher level of TSH level at the time of diagnosis of hypothyroidism than females without diabetes. (Table 5)

Table 5. Difference in TSH level among females with and without diabetes at the time of diagnosis of hypothyroidism

\begin{tabular}{|l|l|l|l|l|l|}
\hline \multirow{2}{*}{$\begin{array}{l}\text { History of } \\
\text { Diabetes }\end{array}$} & \multicolumn{2}{|c|}{ Sex of Participant } & Statistic & \multicolumn{2}{c|}{ 95\% Confidence Interval } \\
\cline { 5 - 6 } & & & \multicolumn{1}{c|}{ Lower } & \multicolumn{1}{c|}{ Upper } \\
\hline Present & Female & Mean & 24.2795 & 11.1235 & 42.0303 \\
\hline & & N & 19 & 19 & 19 \\
\hline & & Std. Deviation & 34.88844 & 7.35747 & 49.53283 \\
\hline Absent & Female & Mean & 11.1813 & 8.7824 & 13.7807 \\
\hline & & N & 32 & 32 & 32 \\
\hline & & Std. Deviation & 7.74764 & 4.26692 & 10.31682 \\
\hline Total & Female & Mean & 16.0610 & 10.9975 & 22.6109 \\
\hline & & N & 51 & 51 & 51 \\
\hline & & Std. Deviation & 22.72257 & 7.44397 & 34.08326 \\
\hline
\end{tabular}

df-1; F-4.216; p value- 0.045 
Study of TSH level at the time of diagnosis of Hypothyroidism Jour of Diab and Endo Assoc of Nepal 2020; 4 (2): (24-28)

\section{Discussion}

This study was done with the purpose to evaluate the difference in the level of TSH among the hypothyroid patients with and without the history of the diabetes at the time of their diagnosis of the hypothyroidism. To our knowledge, this is the first study which has compared the TSH level at the time of diagnosis of hypothyroidism in both group of patients with and without diabetes.

Our study included 100 participants. 50 participants had diabetes when they were diagnosed of having hypothyroidism. 50 hypothyroid patients without the diabetes were taken as control. In the present study, the mean values of serum TSH was $19.9616 \pm 26.990$ $\mu \mathrm{IU} / \mathrm{mL}$ in those with history of diabetes, and was $10.4797 \pm 6.503 \mu \mathrm{IU} / \mathrm{mL}$ in those without the history of the diabetes mellitus. The mean TSH level was higher in those patients with diabetes during the time of their diagnosis of hypothyroidism. This difference in TSH level among those with and without diabetes was statistically significant with the p-value of 0.018 . one of the study conducted by Acharya et al. in Nepal also showed statistically significant difference in the TSH level in patients with and without diabetes with the TSH level being higher in diabetic patients. ${ }^{10}$ Similarly, in the studies done by Prasad et al. and Swamy et al., statistically significant increased level of TSH was found in diabetic patients as compared to non-diabetic patients. ${ }^{11,12}$ These results are similar to that of our study showing increased TSH level in patient with diabetes in comparison to those without diabetes; however these studies used healthy persons as control, whereas we used hypothyroid patients without diabetes as controls in our study. However, in a study done by Islam et al there was no significant difference in the level of TSH among diabetic and non-diabetic patients. ${ }^{13}$

In our study, females with diabetes were found to have higher level of TSH at the time of diagnosis of hypothyroidism than females without diabetes ( $p$ value 0.045 ). Bharat et al. also found statistically significant higher level of TSH in diabetic females in comparison to females without diabetes mellitus. ${ }^{14}$ However study done by Ishay et al. didn't not find the statistically significant difference in TSH between female patients with and without diabetes, which contradicts the results of our study. ${ }^{15}$ In our study, however, there was no statistically significant difference in the TSH level among male patients at the time of diagnosis of hypothyroidism irrespective of the presence or absence of diabetes mellitus.

The elevation of TSH in the diabetic patient might be due to the effect of Hyperinsulinemia and the Leptin on the Hypothalamic-Pituitary-Thyroid Axis resulting in stimulation of TSH secretion. ${ }^{16}$ Undiagnosed or diagnosed elevated TSH level, as seen in hypothyroidism, increases the existing cardiovascular risk and diabetic kidney disease in patients with diabetes mellitus. ${ }^{6,17}$ So, early diagnosis of elevated TSH level in diabetic patients will help in the reduction of mortality and morbidity.

However our study has some limitations. First, this study is a retrospective and observational study and it was tough to avoid selection and confounding bias. Second, the sample size of this study was relatively small. Third, as this study was done at a tertiary referral centre, the results of this study may not be applicable at the community level.

\section{Conclusion}

Patients with diabetes mellitus had higher level of $\mathrm{TSH}$ at the time of diagnosis of hypothyroidism in comparison to those without diabetes. Early identification of the raised TSH levels in diabetic patients and timely intervention will help to reduce the chances of adverse cardiovascular outcomes and diabetic kidney disease in this group of patients.

Also, as elevated TSH is independently related with the insulin resistance, early identification of raised TSH and proper treatment of thyroid dysfunction can reverse the insulin resistance in diabetic patients.

\section{Reference}

1. Uppal V, Vij C, Bedi GK, Vij A, Banerjee BD. Thyroid disorders in patients of type 2 diabetes mellitus. Indian $\mathrm{J}$ Clin Biochem. 2013;28(4):336-41.

2. Perros P, McCrimmon RJ, Shaw G, Frier BM. Frequency of thyroid dysfunction in diabetic patients: value of annual screening. Diabetic medicine : a journal of the British Diabetic Association. 1995;12(7):622-7.

3. Radaideh AR, Nusier MK, Amari FL, Bateiha AE, El-Khateeb MS, Naser AS, et al. Thyroid dysfunction in patients with type 
2 diabetes mellitus in Jordan. Saudi Med J. 2004;25(8):1046-50.

4. Hallengren B. [Hypothyroidism--clinical findings, diagnosis, therapy. Thyroid tests should be performed on broad indications]. Lakartidningen. 1998;95(38):4091-6.

5. Udovcic M, Pena RH, Patham B, Tabatabai L, Kansara A. Hypothyroidism and the Heart. Methodist Debakey Cardiovasc J. 2017;13(2):55-9.

6. Qi Q, Zhang Q-M, Li C-J, Dong R-N, Li J-J, Shi J-Y, et al. Association of Thyroid-Stimulating Hormone Levels with Microvascular Complications in Type 2 Diabetes Patients. Med Sci Monit. 2017;23:2715-20.

7. Zhu P, Liu X, Mao X. Thyroid-Stimulating Hormone Levels Are Positively Associated with Insulin Resistance. Med Sci Monit. 2018;24:342-7.

8. Centanni M, Benvenga S, Sachmechi I. Diagnosis and management of treatmentrefractory hypothyroidism: an expert consensus report. J Endocrinol Invest. 2017;40(12):1289-301.

9. Bensenor IM, Olmos RD, Lotufo PA. Hypothyroidism in the elderly: diagnosis and management. Clin Interv Aging. 2012;7:97111.

10. Arun Acharya PBS, Ekta Chitrakar, Sabina Shrestha. Evaluation of Thyroid Hormone Level in Patients with Type 2 Diabetes Mellitus as Compared to Normal Individuals in Nepal. International Journal of Health Sciences and Research. 2017;7(1):79-85.
11. D. K. V. P, T. S. PR, G. KM. Prevalence of thyroid dysfunction and its association with controlled and uncontrolled type 2 diabetes mellitus in northern Andhra Pradesh population: a retrospective study. 2017. 2017;5(9):6.

12. Rm S, Kumar N, Narasimhaiah M, Ds P. Evaluation of hypothyroidism as a complication in Type II Diabetes Mellitus. Biomedical Research. 2011;23.

13. Islam S, Yesmine S, Khan SA, Alam NH, Islam S. A comparative study of thyroid hormone levels in diabetic and non-diabetic patients. The Southeast Asian journal of tropical medicine and public health. 2008;39(5):9136.

14. Bharat DH, David Gangte, Lalnunpui, Premchand, Ibetombi Devi and Gyaneshwar W Singh. Thyroid Status in Diabetes Mellitus. Journal of Glycomics \& Lipidomics. 2013;3(1):1-4.

15. Ishay A, Chertok-Shaham I, Lavi I, Luboshitzky R. Prevalence of subclinical hypothyroidism in women with type 2 diabetes. Med Sci Monit. 2009;15(4):Cr1515.

16. Ortiga-Carvalho TM, Oliveira KJ, Soares BA, Pazos-Moura CC. The role of leptin in the regulation of TSH secretion in the fed state: in vivo and in vitro studies. The Journal of endocrinology. 2002;174(1):121-5.

17. Díez JJ, Iglesias P. An analysis of the relative risk for hypothyroidism in patients with Type2 diabetes. Diabetic Medicine. 2012;29(12):1510-4. 